\title{
Rapid preparation of mutated influenza hemagglutinins for influenza virus pandemic prevention
}

\author{
Ryosuke Nishioka', Atsushi Satomura1,2, Junki Yamada'1, Kouichi Kuroda and Mitsuyoshi Ueda ${ }^{1 *}$
}

\begin{abstract}
Influenza viruses have periodically caused pandemic due to frequent mutation of viral proteins. Influenza viruses have two major membrane glycoproteins: hemagglutinin (HA) and neuraminidase (NA). Hemagglutinin plays a crucial role in viral entry, while NA is involved in the process of a viral escape. In terms of developing antiviral drugs, HA is a more important target than NA in the prevention of pandemic, since HA is likely to change the host specificity of a virus by acquiring mutations, thereby to increase the risk of pandemic. To characterize mutated HA functions, current approaches require immobilization of purified HA on plastic wells and carriers. These troublesome methods make it difficult to respond to emerging mutations. In order to address this problem, a yeast cell surface engineering approach was investigated. Using this technology, human HAs derived from various H1N1 subtypes were successfully and rapidly displayed on the yeast cell surface. The yeast-displayed HAs exhibited similar abilities to native influenza virus HAs. Using this system, human HAs with 190E and 225G mutations were shown to exhibit altered recognition specificities from human to avian erythrocytes. This system furthermore allowed direct measurement of HA binding abilities without protein purification and immobilization. Coupled with the ease of genetic manipulation, this system allows the simple and comprehensive construction of mutant protein libraries on yeast cell surface, thereby contributing to influenza virus pandemic prevention.
\end{abstract}

Keywords: Influenza, Hemagglutinin, Yeast display, Hemagglutination assay

\section{Introduction}

Influenza viruses have caused pandemic in humans as well as in animals (Potter 2001; Capua and Alexander 2008). The human influenza viruses recognize human-specific cell receptors via $\alpha 2,6$-linked sialic acid side chains on surface glycoproteins, while avian influenza viruses recognize avian-specific cell receptors via $\alpha 2,3$-linked sialic acid side chains on surface glycoproteins (Gagneux et al. 2003; Ito and Kawaoka 2000). These subtle differences in sialic acid recognition are key in preventing animal influenza viruses from infecting humans; however, some influenza viruses infecting animals have acquired the potency to overcome this difference (Van Reeth 2007). Highly

\footnotetext{
*Correspondence: miueda@kais.kyoto-u.ac.jp

${ }^{1}$ Division of Applied Life Sciences, Graduate School of Agriculture, Kyoto

University, Sakyo-Ku, Kyoto 606-8502, Japan

Full list of author information is available at the end of the article
}

pathogenic avian influenza viruses including H5N1 subtypes have been reported to alter their targets from avian to human, causing 447 deaths until 2010 (Webby and Webster 2003; WHO 2015). Recently, the swine influenza virus also acquired the ability to infect humans via genetic re-assortment (Zhou et al. 1999). The swine influenza virus was transmitted widely among humans, resulting in the first influenza pandemic in the twenty first century (Kuiken et al. 2011). Swine may play roles as intermediate hosts for influenza viruses between humans and avian species because swine cell receptors have both the $\alpha 2,6$ and the $\alpha 2,3$-linked sialic acid side chains on their surface glycoproteins (Ito and Kawaoka 2000). When human influenza viruses and avian influenza viruses infect the same intermediate host, gene re-arrangement between the human and avian influenza viruses is likely to occur, enabling the viruses to alter their recognition preferences of sialic acid on surface glycoprotein (Dawood et al. 2009).

\section{Springer}


Indeed, the influenza virus pandemic is thought to have emerged from gene re-assortment of the North American H3N2 human-like viruses and the H1N2 swine viruses with Eurasian avian-like swine viruses (Dawood et al. 2009). The re-assortment process enables animal influenza viruses to effectively develop the capacity to infect humans (Zhou et al. 1999), which suggests that the threat of infection caused by new influenza viruses will continue as the differences between human and animal viruses are overcome.

Influenza viruses have two major surface membrane glycoproteins: neuraminidase (NA) and hemagglutinin (HA) (Air and Laver 1989; Skehel and Wiley 2000). While NA is involved in the process by which newly generated viruses escape from host cells (Air and Laver 1989), HA, which forms a trimer embedded on the viral envelope surface, is responsible for binding and entry into host cells (Skehel and Wiley 2000). Each monomer of HA is synthesized as a single polypeptide (HA0) that is cleaved by host proteases into two subunits (HA1 and HA2) (Skehel and Wiley 2000), of which HA1 represents an active head region that binds to sialic acid side chains on surface glycoproteins and HA2 represents a stem region that is required for membrane fusion activity and infectivity (Skehel and Wiley 2000). Both NA and HA are frequently mutated in the life cycle of the influenza virus, resulting in high levels of antigenic variation (Domingo and Holland 1997).

The high mutation rate of $\mathrm{HA}$ sometimes generates new HA subtypes that have never infected humans. Some mutations have already been reported to contribute to the changes in the binding abilities of HA from avian to human receptors or from human to avian receptors, which were, in part, responsible for the pandemic (Stevens et al. 2006). Inhibition of HA prevents the infection as a first attack caused by influenza virus mutants. Various methods including phage display have been used to screen for inhibitors that bind to the target domains (Hawkins et al. 1992; Matsubara et al. 2010; Krag et al. 2006); however, these current approaches would not be sufficient to deal with influenza viruses for the following reasons. Firstly, in order to discriminate the binding abilities of HA mutants, purified HA needs to be immobilized on plastic wells or carriers (Hawkins et al. 1992; Matsubara et al. 2010). Secondly, frequent mutations make it difficult to deal with HA mutants because time-consuming methods are required for each mutant preparation. In order to address these problems, a novel method for dealing with the high mutation rate of the influenza virus must be developed.

We previously reported on the successful display of various head domains of the wild-type and drug-resistant
NAs from the avian H5N1 virus on yeast cell surface using yeast cell surface engineering in Saccharomyces cerevisiae (Shigemori et al. 2013). In this system, a protein of interest can be displayed on yeast cell surface as a fusion protein with $\alpha$-agglutinin, which is a cell wall protein involved in mating (Murai et al. 1997; Ueda and Tanaka 2000). This method allows direct measurement of the protein activity without protein purification steps (Ueda and Tanaka 2000).

Here, we report on the construction of two kinds of yeasts displaying either human short $\mathrm{HA}\left(\mathrm{hSHA}^{\alpha 2,6}\right)$ or human long HA (hLHA $\left.{ }^{\alpha 2,6}\right)$ from the human H1N1 virus. $\mathrm{hSHA}^{\alpha 2,6}$ consists of the domain that binds to $\alpha 2,6$-linked sialic acid side chains, while hLHA ${ }^{\alpha 2,6}$ consists of the binding domain and the stem region without the secretion signal peptide and the transmembrane domain. hSHA ${ }^{\alpha 2,6}$ and $\mathrm{hLHA}^{\alpha 2,6}$ displayed on the yeast cell surface were shown to recognize $\alpha 2,6$-linked sialic acid side chains on the surface glycoproteins of erythrocytes. The cell surface display of human HA mutants with altered binding specificity by induction of mutations was furthermore shown to result in direct detection of recognizing $\alpha 2$,3-linked sialic acid side chains on chicken erythrocytes. The system reported on here was shown to rapidly prepare HA mutants on cell surface and to allow for easy analysis of the functions of these mutants coupled with easy genetic manipulation of yeast. Our yeast cell surface system therefore allows for the simple and comprehensive construction of HA and NA mutant libraries on yeast cell surface, thereby facilitating the prevention of pandemic caused by influenza viruses.

\section{Materials and methods}

\section{Microbial strains and culture media}

The DH5 $\alpha\left(\mathrm{F}^{-}\right.$, endA $1, h s d \mathrm{R} 17\left[\mathrm{r}_{\mathrm{k}}^{-} / \mathrm{m}_{\mathrm{K}}^{+}\right]$, supE44, thi-1, $\lambda^{-}$, deoR, recA1, gyrA96, phoA, $\phi 80 \mathrm{~d} l a c \mathrm{Z} \Delta \mathrm{M} 15, \Delta[$ lacZYAargF]U169) Escherichia coli strain (Toyobo, Osaka, Japan) was used as the host for recombinant DNA manipulation. S. cerevisiae BY4741/sed1 $\Delta$ (MATa, his $3 \Delta 1$, leu $2 \Delta 0$, met15 $\Delta 0$, ura3 $\Delta 0$, YDR077w::KanMX4) (EUROSCARF, Frankfurt, Germany) was used for displaying HA. E. coli transformants were grown at $37{ }^{\circ} \mathrm{C}$ in Luria-Bertani medium $(1 \%[\mathrm{w} / \mathrm{v}]$ tryptone, $0.5 \%[\mathrm{w} / \mathrm{v}]$ yeast extract, and $1 \%[\mathrm{w} / \mathrm{v}]$ sodium chloride) containing $50 \mu \mathrm{g} / \mathrm{mL}$ ampicillin. Yeast transformants were selected on a synthetic dextrose (SDC) solid medium $(0.67 \%$ [w/v] yeast nitrogen base without amino acids, $2 \%[\mathrm{w} / \mathrm{v}]$ glucose, $1 \%[\mathrm{w} / \mathrm{v}$ ] casamino acids, $0.002 \%[\mathrm{w} / \mathrm{v}$ ] adenine, $0.002 \%$ [w/v] L-tryptophan, $2 \%[\mathrm{w} / \mathrm{v}]$ agar). Isolated transformant colonies were aerobically cultivated at $30{ }^{\circ} \mathrm{C}$ in a liquid SDC medium buffered with $5 \mathrm{mM}$ 2-morpholinoethanesulfonic acid (MES; pH 6.5). 


\section{Vectors for cell surface display of human HA}

The primers used in this study are listed in Additional file 1: Table S1. The human HA gene was derived from the Influenza A H1N1 (A/New Caledonia/20/99) HA ORF mammalian expression plasmid (Sino Biological, Beijing, China). The DNA fragments encoding a binding domain (human short HA, amino acid residues No. 36-268) or encoding a binding domain and stem region (human long HA, amino acid residues No. 14-515) were PCR-amplified from the plasmid using the appropriate primers ("human short HA Forward" and "human short HA Reverse" for human short HA, or "human long HA Forward" and "human long HA Reverse" for human long $\mathrm{HA}$ ). The DNA fragments were inserted into BglII/XhoIdigested pULD1 (Kuroda et al. 2009), which encodes the $C$-terminal half of $\alpha$-agglutinin downstream of the multiple cloning sites, using an In-Fusion HD Cloning kit (Clontech, Mountain view, CA). The resultant plasmids were named pULD-hSHA ${ }^{\alpha 2,6}$ and pULD-hLHA ${ }^{\alpha 2,6}$. The plasmids used for displaying the head domain recognizing $\alpha 2,3-$ linked sialic acid side chains on surface glycoproteins were constructed by mutating pULD-hSHA ${ }^{\alpha 2,6}$ or pULD-hLHA ${ }^{\alpha 2,6}$ using a QuikChange Site-Directed Mutagenesis kit (Agilent Technologies, Santa Clara, $\mathrm{CA}$ ) and the "N190E Forward" and "N190E Reverse" or "D225G Forward" and "D225G Reverse" primers. The resultant plasmids were named pULD-hSHA ${ }^{\alpha 2,6^{*}}$ and pULD-hLHA ${ }^{\alpha 2,6^{*}}$, respectively. pULD1-strep displaying a strep-tag instead of a FLAG-tag, was used as a negative control for immunofluorescence staining (Kuroda et al. 2009).

\section{Transformation of yeast}

Yeasts were transformed using the Frozen-EZ Yeast Transformation-II kit (Zymo Research, Irvine, CA). After the introduction of plasmids, the yeast transformants were selected on a uracil-deficient SDC solid medium.

\section{Collection and preparation of red blood cells}

Rabbit, chicken, horse (Nippon Biotest Laboratories, Tokyo, Japan), and swine (Funakoshi, Tokyo, Japan) erythrocytes were used for the HA assay. Aliquots $(4 \mathrm{~mL})$ of erythrocytes were washed three times with phosphatebuffered saline (PBS; $\mathrm{pH} 7.4$ ) by centrifugation at $100 \times g$ for $10 \mathrm{~min}$, and were then resuspended in PBS (pH 7.4) at final working solution (1.0\%).

\section{Hemagglutination assay}

Yeast transformants were precultivated in buffered SDC medium ( $\mathrm{pH}$ 6.5) for $24 \mathrm{~h}$ and the main cultivation was initiated at an initial optical density $\left(\mathrm{OD}_{600}\right)$ of $0.1 \mathrm{in} 10 \mathrm{~mL}$ buffered SDC medium (pH 6.5). After $72 \mathrm{~h}$ cultivation at $30{ }^{\circ} \mathrm{C}$, the cells were harvested and resuspended to $2.0 \times 10^{8}$ cells $/ \mathrm{mL}$. Cell suspensions $(50 \mu \mathrm{L})$ were diluted 2-, 4-, and 8-fold with PBS (pH 7.4) in a 96-well microplate (FALCON 353910, CA). The yeast cells were mixed with $50 \mu \mathrm{L}$ erythrocyte suspension (1.0\%) and incubated at $25{ }^{\circ} \mathrm{C}$ for $2 \mathrm{~h}$. Active HA yields the "cross-linked structure", while HA lacking binding ability forms "dot-like aggregation" in the center of the well (see Fig. 2). To investigate the relative binding abilities of HA, a quantitative analysis of dot-like aggregation in the well was performed using ImageJ software (National Institutes of Health, MD) (Lazic 2009). Images were analyzed after background correction using the rolling ball radius tool (50 pixels). The area of "dot-like aggregation" of erythrocytes within each negative control well $\left(\mathrm{OD}_{600}=10\right)$ was defined as the measurement area, which was then used to evaluate erythrocyte levels as raw integrated density values (sum of pixel values) in other wells $\left(\mathrm{OD}_{600}=10\right)$ (Lazic 2009). The results of this analysis were shown as the ratio to negative controls from each of six separate images (Additional file 1: Figure S1). Differences found to be significant by the Steel-Dwass test $(P<0.01)$ were considered to be indicative of HA binding ability.

\section{Immunofluorescent staining}

A total of $3.0 \times 10^{7}$ yeast cells were washed once with $1 \mathrm{~mL}$ PBS (pH 7.4) and then resuspended in PBS (pH 7.4) containing $1.0 \%(\mathrm{w} / \mathrm{v})$ bovine serum albumin. The yeast cells were incubated at room temperature for $30 \mathrm{~min}$ with rotary shaking $(25 \mathrm{rpm}$; RT-50, TAITEC, Saitama, Japan). The yeast cells were incubated with an anti-FLAG M2 mouse monoclonal antibody (Sigma-Aldrich, MO) at a 1:300 dilution for $1.5 \mathrm{~h}$ at room temperature. The yeast cells were washed with $\mathrm{PBS}(\mathrm{pH}$ 7.4) and mixed with Alexa Flour 488-conjugated anti-mouse IgG antibody (Invitrogen, Carlsbad, CA) at a 1:300 dilution for $1 \mathrm{~h}$ at room temperature. After washing twice with PBS ( $\mathrm{pH}$ 7.4), the yeast cells were resuspended to $10^{8}$ cells/ $\mathrm{mL}$ by PBS ( $\mathrm{pH}$ 7.4) for fluorescence observation. Fluorescence was detected using an inverted microscope (Olympus IX71, Tokyo, Japan) through a U-MNIBA2 mirror unit with a BP470-490 excitation filter, DM505 dichroic mirror, and a BA510-550 emission filter (Olympus). Live images were obtained using Aqua-Cosmos 2.0 software (Hamamatsu Photonics, Shizuoka, Japan) controlling a digital charge-coupled device camera (C474295-12ER, Hamamatsu Photonics). To determine the display efficiency, the fluorescence intensities were measured by using a Fluoroskan Ascent Fluorometer (Labsystems, Helsinki, Finland) with excitation and emission wavelengths of 485 and $527 \mathrm{~nm}$, respectively. A total of $2.0 \times 10^{7}$ yeast cells were used for measurement. 


\section{Results}

\section{Display of human HAs on the yeast cell surface}

The HA0 protein of influenza viruses reportedly needs to be cleaved by host proteases to yield two subunits, HA1 and HA2 (Skehel and Wiley 2000; Stieneke-Grober et al. 1992). In the current study, two kinds of yeasts displaying human short $\mathrm{HA}\left(\mathrm{hSHA}^{\alpha 2,6}\right)$ and human long HA (hLHA ${ }^{\alpha 2,6}$ ) were constructed (Additional file 1: Figure S2). $\mathrm{hSHA}^{\alpha 2,6}$ contains only the $\alpha 2,6$-linked sialic acid binding site (HA1), while hLHA ${ }^{\alpha 2,6}$ contains both the sialic acid binding site and the stem domain (HA1 and HA2) (Fig. 1a). Fluorescent signals due to hHAs ${ }^{\alpha 2,6}$ $\left(\mathrm{hSHA}^{\alpha 2,6}\right.$ and $\left.\mathrm{hLHA}^{\alpha 2,6}\right)$ were detected on the yeast cell surface following immunofluorescence staining (Fig. 1b); however, the fluorescence intensity from yeast cells displaying hLHA ${ }^{\alpha 2,6}$ was lower than that of yeast cells displaying $\mathrm{hSHA}^{\alpha 2,6}$ (Fig. 1c). These results indicate that both $\mathrm{hHAs}^{\alpha 2,6}$ (hSHA $^{\alpha 2,6}$ and $\mathrm{hLHA}^{\alpha 2,6}$ ) were correctly displayed, although $\mathrm{hSHA}^{\alpha 2,6}$ displayed more efficiently than hLHA ${ }^{\alpha 2,6}$.

\section{Binding abilities of yeast-displayed human HAs}

The binding abilities of the human HAs displayed by yeast cells were confirmed by the hemagglutination assay described in "Materials and methods". When active HA binds to sialic acid side chains on surface glycoproteins of

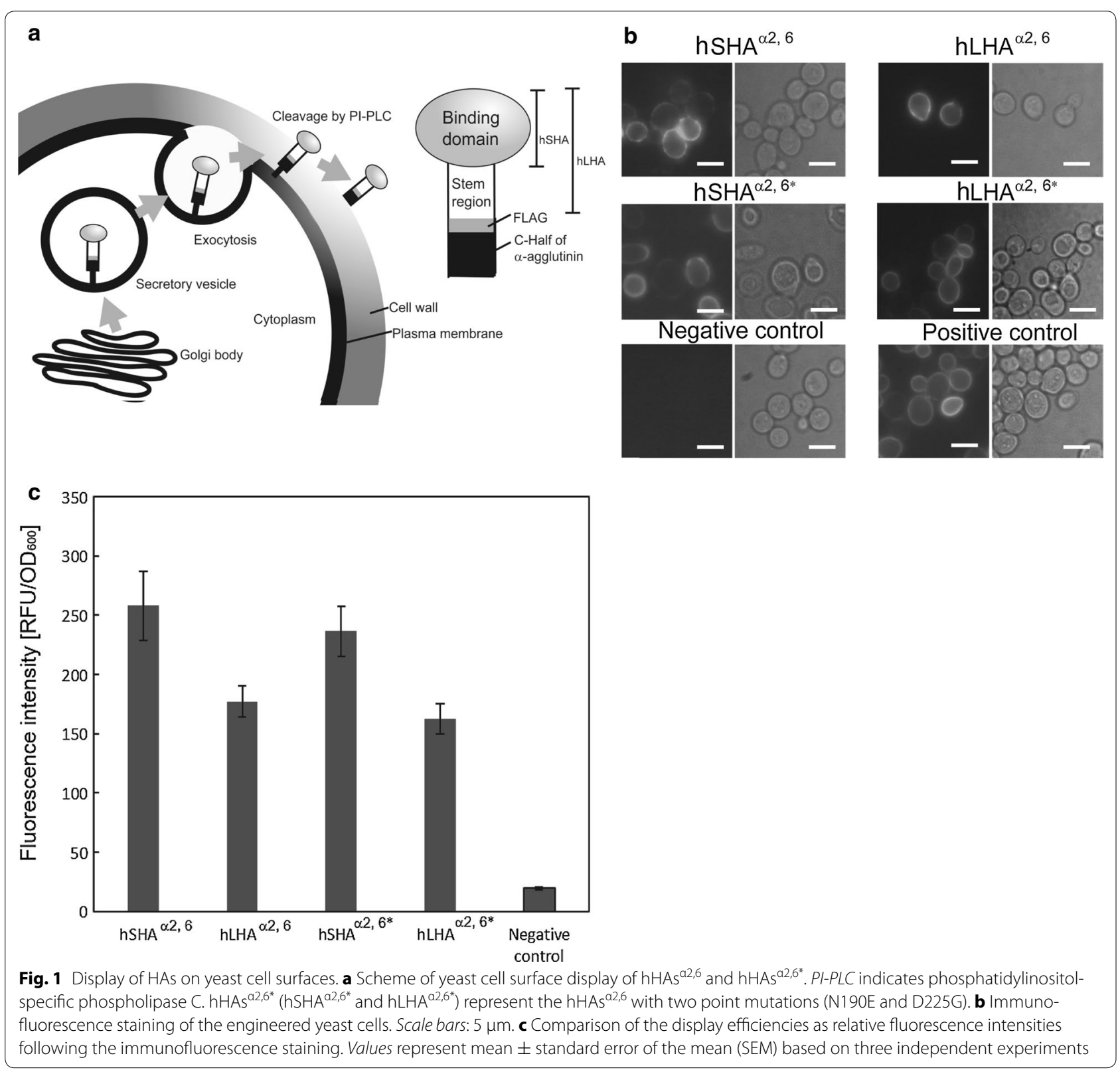


erythrocytes, a "cross-linked structure" is formed, appearing as a uniform reddish color in the culture plate well. In the case of HA lacking these binding capabilities, on the other hand, the cross-linked structure is not formed, and "dotlike aggregation" is formed in the center of the wells instead (Fig. 2). Rabbit erythrocytes, which have $\alpha 2,6$-linked sialic acid side chains on their surface glycoproteins (Tumpey et al. 2007), were initially used in this study. The hSHA ${ }^{\alpha 2,6}$ and $\mathrm{hLHA}^{\alpha 2,6}$ displayed on yeast cell surface were found to form cross-linkages with the rabbit erythrocyte cells, while the yeast cells displaying only the FLAG-tag (negative control) did not form such cross-linkages (Fig. 3a). To evaluate the relative binding abilities of $\mathrm{HA}$, the sum of pixel values within each well was measured as described in "Materials and methods". Significant differences were measured between the negative control and $\mathrm{hSHA}^{\alpha 2,6}$ as well as between the negative control and hLHA $^{\alpha 2,6}$ (Additional file 1: Figure S1). These results indicate that the HA-displaying yeasts recognized $\alpha 2,6$-linked sialic acid side chains on surface glycoproteins of rabbit erythrocytes.

\section{Binding preferences of mutated human HAs on yeast cell surfaces}

To further characterize HA on the yeast cell surface, we investigated whether the altered binding site affected the recognition properties of the displayed HA. On the virus surface, HA distinguishes between $\alpha 2,3-$ and $\alpha 2,6$-linked sialic acid side chains (Ito et al. 1997). In general, influenza viruses isolated from humans bind to $\alpha 2,6$ - but not $\alpha 2,3$-linked sialic acid side chains (Gagneux et al. 2003); however, the $190 \mathrm{E}$ and $225 \mathrm{G}$ mutations in HAs derived from the human $\mathrm{H} 1$ subtype reportedly yielded a change

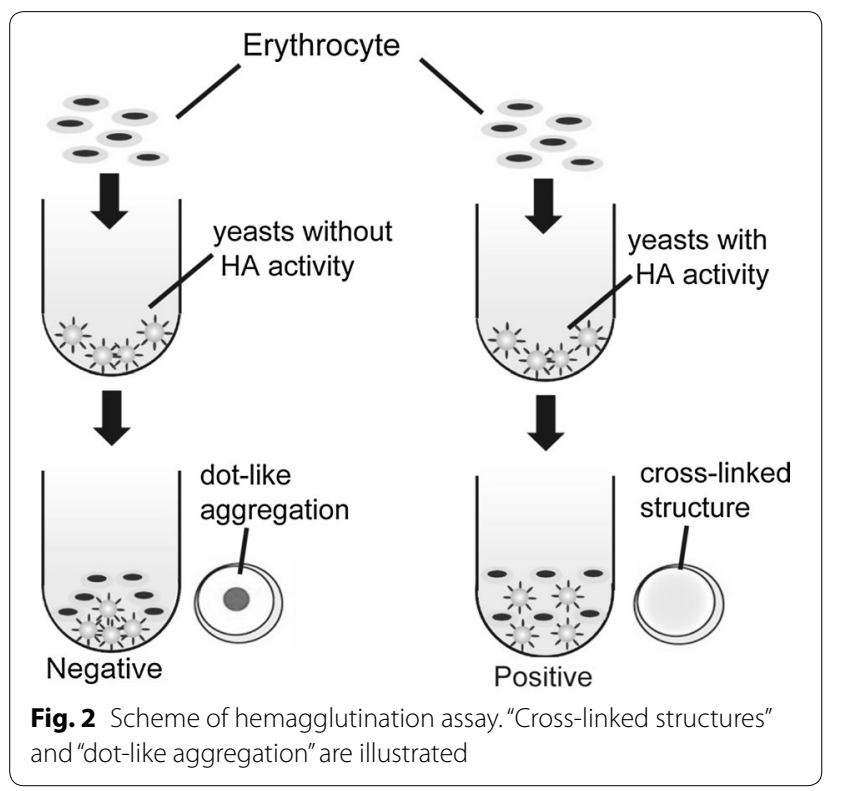

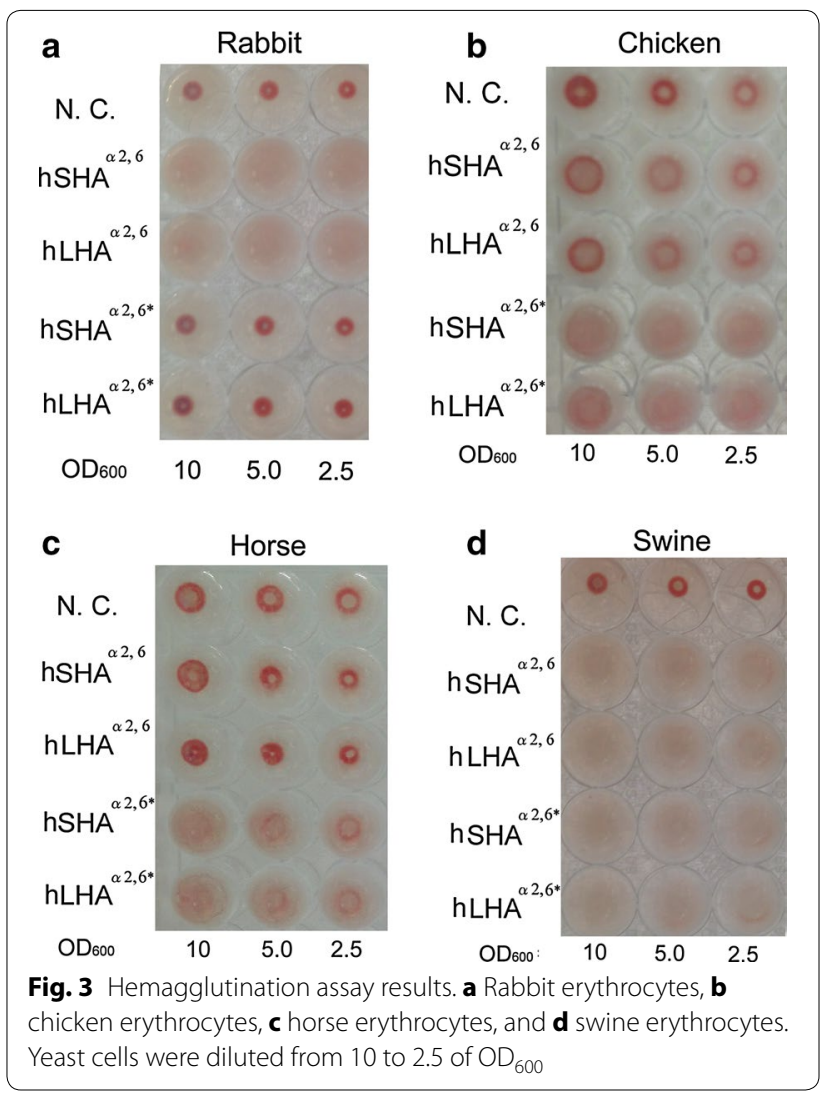

in recognition from $\alpha 2,6$ - to $\alpha 2,3$-linked sialic acid side chains (Tumpey et al. 2007). Recognition change can be confirmed using erythrocytes from different hosts (Ito et al. 1997). Chicken erythrocytes, for example, contain more $\alpha 2,3$ - than $\alpha 2,6$-linked sialic acid side chains, while rabbit erythrocytes contain mainly $\alpha 2,6$-linked sialic acid side chains (Tumpey et al. 2007). We investigated in this study whether the introduction of two point mutations (N190E and D225G) into hHAs ${ }^{\alpha 2,6}$ altered the recognition from $\alpha 2,6$ - to $\alpha 2,3$-sialic acid side chains. Humanbased short HA (hSHA ${ }^{\alpha 2,6^{*}}$ ) and human-based long HA $\left(\mathrm{hLHA}^{\left.\alpha 2,6^{*}\right)}\right.$ were constructed by introducing the two point mutations (N190E and D225G) into hSHA ${ }^{\alpha 2,6}$ and $\mathrm{hLHA}^{\alpha 2,6}$ (Additional file 1: Figure S2). Display of $\mathrm{hSHA}^{\alpha 2,6^{*}}$ and $\mathrm{hLHA}^{\alpha 2,6^{*}}$ on yeast cells was confirmed by immunofluorescence (Fig. 1b, c). The yeast-displayed $\mathrm{hSHA}^{\alpha 2,6^{*}}$ and $\mathrm{hLHA}^{\alpha 2,6^{*}}$ exhibited binding capabilities for $\alpha 2,3$-linked sialic acid side chains on surface glycoproteins of erythrocyte derived from chicken, while hHAs ${ }^{\alpha 2,6}$ did not (Fig. 3b; Additional file 1: Figure S1). Therefore, the two point mutations were shown to alter recognition from $\alpha 2,6$ - to $\alpha 2,3-$ linked sialic acid side chains, suggesting that the HAs on yeast cell surfaces exhibited similar binding characteristics to those of native HAs on the virus. 
The binding preferences of $\mathrm{hHAs}^{\alpha 2,6}$ and $\mathrm{hHAs}{ }^{\alpha 2,6^{*}}$ (hSHA $^{\alpha 2,6^{*}}$ and hLHA ${ }^{\alpha 2,6^{*}}$ ) toward horse and swine erythrocytes were investigated. Horse erythrocytes contain mainly $\alpha 2,3$-linked sialic acid side chains on surface glycoproteins and swine erythrocytes contain both $\alpha 2,3-$ and $\alpha 2,6$-linked sialic acid side chains on their surface glycoproteins (Ito et al. 1997). hHAs ${ }^{\alpha 2,6^{*}}$ was shown to form cross-linkages with the horse erythrocytes (Fig. 3c; Additional file 1: Figure S1) and in the case of the swine erythrocytes, both hHAs ${ }^{\alpha 2,6}$ and hHAs ${ }^{\alpha 2,6^{*}}$ formed crosslinkages (Fig. 3d; Additional file 1: Figure S1). Overall, $\mathrm{hHAs}^{\alpha 2,6}$ were therefore shown to recognize rabbit and swine erythrocytes, while hHAs ${ }^{\alpha 2,6^{*}}$ was shown to recognize chicken, horse, and swine erythrocytes. These recognition specificities are consistent with the distribution of sialic acid side chains on the respective surface glycoproteins (Ito et al. 1997; Medeiros et al. 2001).

\section{Discussion}

In this study, the binding sites of hHAs ${ }^{\alpha 2,6}$ and hHAs ${ }^{\alpha 2,6^{*}}$ were successfully displayed on yeast cell surface (Fig. 1b). The binding abilities of the displayed $h \mathrm{HAs}^{\alpha 2,6}$ were evaluated by hemagglutination assay using rabbit erythrocytes whose surface glycoproteins contain $\alpha 2,6$-linked sialic acid side chains (Fig. 3a; Additional file 1: Figure S1). Altered recognition of $\mathrm{HA}$ to $\alpha 2,3$-linked sialic acid side chains was achieved by mutagenesis (Fig. 3b: Additional file 1: Figure S1). The displayed $\mathrm{hHAs}^{\alpha 2,}{ }^{*}$ recognized $\alpha 2,3$-linked sialic acid side chains of chicken erythrocyte surface glycoproteins. The relative binding abilities of hHAs $^{\alpha 2,6}$ and $\mathrm{hHAs}^{\alpha 2,6^{*}}$ toward erythrocytes derived from various species were assessed, and differences between HAs and negative controls, significant by the Steel-Dwass test $(P<0.01)$, were considered indicative of binding capacity of the HA in question (Additional file 1: Figure S1). Chicken erythrocytes contain mainly $\alpha 2,3-$ and $\alpha 2,6-$ linked sialic acid side chains of surface glycoproteins (Medeiros et al. 2001). In this study, hHAs ${ }^{\alpha 2,6}$ did not form cross-linkages with chicken erythrocytes (Fig. 3b; Additional file 1: Figure S1) and the number of $\alpha 2,6-$ linked sialic acid side chains on the chicken erythrocytes was thus considered insufficient for cross-linkages to form (Table 1). The hHAs ${ }^{\alpha 2,6^{*}}$ formed cross-linkages with horse erythrocytes (Fig. 3c; Additional file 1: Figure S1) and both the $\mathrm{hHAs}^{\alpha 2,6}$ and the $\mathrm{hHAs}{ }^{\alpha 2,6^{*}}$ formed cross-linkages with swine erythrocytes (Fig. 3d; Additional file 1: Figure $\mathrm{S} 1)$. These findings suggest that the two amino acid substitutions ((N190E and D225G) in the HAs on the yeast cell surfaces altered the HA binding preferences, which is in agreement with previously reported findings (Ito et al. 1998). These results demonstrate that the yeast cell surface display system described here is a promising strategy for preparing functional HA mutants.

\section{Table 1 Hemagglutination assay with erythrocytes from different animal species}

\begin{tabular}{|c|c|c|c|c|}
\hline & \multicolumn{4}{|c|}{ Hemagglutination with erythrocytes from } \\
\hline & Rabbit & Chicken & Horse & Swine \\
\hline Relative abundance ${ }^{a}$ & $a 2,6$ & $a 2,6<<a 2,3$ & $a 2,3$ & $a 2,6=a 2,3$ \\
\hline Binding activity of $\mathrm{HAs}^{\mathrm{a} 2,6}$ & + & - & - & + \\
\hline Binding activity of $\mathrm{HAs}^{\mathrm{a} 2,6^{*}}$ & - & + & + & + \\
\hline
\end{tabular}

"+" indicates positive binding abilities and "-" indicates no abilities

a Distribution of sialic acid-side chains on surface glycoproteins of the erythrocytes from animal species (Ito et al. 1997; Medeiros et al. 2001)

In the yeast cell surface engineering reported here, both $\mathrm{hSHA}^{\alpha 2,6}$ and $\mathrm{hLHA}^{\alpha 2,6}$ were successfully displayed on the yeast cell surface (Fig. 1b). Both hSHA ${ }^{\alpha 2,6}$ and hLHA $^{\alpha 2,6}$ were shown to have similar binding capabilities (Fig. 3a; Additional file 1: Figure S1), suggesting that the yeast-displayed $\mathrm{hLHA}^{\alpha 2,6}$ did not require proteasemediated cleavage for its binding capabilities (Stevens et al. 2006). Glycan arrays have been used to investigate the binding abilities of HA (Stevens et al. 2006; Kumari et al. 2007). For such glycan arrays, HA cleavage by protease treatments was not required for assessments of the binding abilities of HA (Stevens et al. 2006; Kumari et al. 2007). Similarly, HAs displayed on yeast cell surfaces exhibited binding abilities without HA processing by exogenous proteases. Unlike glycan arrays (Stevens et al. 2006; Kumari et al. 2007), yeast cell surface engineering does not require time-consuming purification and immobilization steps. In glycan arrays, HA must be directly or indirectly labelled with a fluorescent tag to allow for binding events to be detected (Stevens et al. 2006). Because of the weak affinity of HA for sialic acids of proteins, glycan arrays sometimes fail to detect binding events (Stevens et al. 2006; Sauter et al. 1989). The display of HA on yeast cell surfaces, on the other hand, may represent a convenient approach by which HA binding specificities can be confirmed.

Recombinant baculoviruses are widely used to express HA genes in cultured insect cells (Wang et al. 2006; Treanor et al. 2013); however, HA production using this approach may take more than a month (Wang et al. 2006; Treanor et al. 2013). With the yeast display method, on the other hand, HA can be prepared within several days and does not require purification.

Human HA consisting of only the binding site (hSHA) was displayed approximately 1.5 times more effectively than human HA consisting of both the binding site and the stem region (hLHA) (Fig. 1b, c). The molecular mass of displayed proteins on the yeast cell surface affects fluorescence intensities of cells after immunofluorescent staining (Nishitani et al. 2010; Shibasaki et al. 2001). Both 
hSHA and hLHA exhibited binding abilities; however, hLHA-displaying yeasts would be more useful in inhibitor screening assays since it is more likely that inhibitors would bind not only to the binding site but also to the stem region.

In conclusions, a yeast cell surface system reported on here allows for direct measurement of the binding abilities of HAs without protein purification steps and thus would allow for the preparation of an HA mutant library as well as an NA mutant library as previously reported (Shigemori et al. 2013). This application would be advantageous in the analysis of newly emerging influenza virus mutants, thereby contributing to the prompt development of antiviral drugs. This yeast cell surface display system would therefore contribute to the prevention of influenza virus pandemics caused by frequent viral mutations.

\section{Additional file}

Additional file 1. List of primers used in this study (Table S1). Box plots showing the ratio of sum of pixel values for (A) rabbit, (B) chicken, (C) horse, and (D) swine erythrocytes (Fig. S1). Sequence alignment of $\mathrm{hHAs}^{\mathrm{a}, 6}$ and hHAs${ }^{\mathrm{a} 2,6^{*}}$ (Fig. S2).

\section{Author details}

${ }^{1}$ Division of Applied Life Sciences, Graduate School of Agriculture, Kyoto University, Sakyo-Ku, Kyoto 606-8502, Japan. ${ }^{2}$ Japan Society for the Promotion of Science, Sakyo-Ku, Kyoto 606-8502, Japan.

\section{Acknowledgements}

This work was partly supported by JST, CREST.

\section{Competing interests}

The authors declare that they have no competing interests.

Received: 12 December 2015 Accepted: 12 January 2016

Published online: 21 January 2016

\section{References}

Air GM, Laver WG. The neuraminidase of influenza virus. Proteins. 1989;6(4):341-56

Capua I, Alexander DJ. Ecology, epidemiology and human health implications of avian influenza viruses: why do we need to share genetic data? Zoonoses Public Health. 2008:55(1):2-15.

Dawood FS, Jain S, Finelli L, Shaw MW, Lindstrom S, Garten RJ, Gubareva LV, Xu $X$, Bridges $C B$, Uyeki TM. Emergence of a novel swine-origin influenza $A$ (H1N1) virus in humans. N Engl J Med. 2009;360(25):2605-15.

Domingo E, Holland JJ. RNA virus mutations and fitness for survival. Annu Rev Microbiol. 1997;51:151-78.

Gagneux P, Cheriyan M, Hurtado-Ziola N, van der Linden EC, Anderson D, McClure H, Varki A, Varki NM. Human-specific regulation of a2-6-linked sialic acids. J Biol Chem. 2003;278(48):48245-50.

Hawkins RE, Russell SJ, Winter G. Selection of phage antibodies by binding affinity. Mimicking affinity maturation. J Mol Biol. 1992;226(3):889-96.

Ito T, Couceiro JN, Kelm S, Baum LG, Krauss S, Castrucci MR, Donatelli I, Kida H, Paulson JC, Webster RG, Kawaoka Y. Molecular basis for the generation in pigs of influenza A viruses with pandemic potential. J Virol. 1998;72(9):7367-73.
Ito T, Kawaoka Y. Host-range barrier of influenza A viruses. Vet Microbiol. 2000;74(1-2):71-5.

Ito T, Suzuki Y, Mitnaul L, Vines A, Kida H, Kawaoka Y. Receptor specificity of influenza A viruses correlates with the agglutination of erythrocytes from different animal species. Virology. 1997;227(2):493-9.

Krag DN, Shukla GS, Shen GP, Pero S, Ashikaga T, Fuller S, Weaver DL, BurdetteRadoux S, Thomas C. Selection of tumor-binding ligands in cancer patients with phage display libraries. Cancer Res. 2006;66(15):7724-33.

Kuiken T, Fouchier R, Rimmelzwaan G, van den Brand J, van Riel D, Osterhaus A. Pigs, poultry, and pandemic influenza: how zoonotic pathogens threaten human health. Adv Exp Med Biol. 2011;719:59-66.

Kumari K, Gulati S, Smith DF, Gulati U, Cummings RD, Air GM. Receptor binding specificity of recent human H3N2 influenza viruses. Virol J. 2007;4:42.

Kuroda K, Matsui K, Higuchi S, Kotaka A, Sahara H, Hata Y, Ueda M. Enhancement of display efficiency in yeast display system by vector engineering and gene disruption. Appl Microbiol Biotechnol. 2009;82(4):713-9.

Lazic SE. Statistical evaluation of methods for quantifying gene expression by autoradiography in histological sections. BMC Neurosci. 2009;10:5.

Matsubara T, Onishi A, Saito T, Shimada A, Inoue H, Taki T, Nagata K, Okahata Y, Sato T. Sialic acid-mimic peptides as hemagglutinin inhibitors for antiinfluenza therapy. J Med Chem. 2010;53(11):4441-9.

Medeiros R, Escriou N, Naffakh N, Manuguerra JC, van der Werf S. Hemagglutinin residues of recent human $\mathrm{A}(\mathrm{H} 3 \mathrm{~N} 2)$ influenza viruses that contribute to the inability to agglutinate chicken erythrocytes. Virology. 2001;289(1):74-85.

Murai T, Ueda M, Yamamura M, Atomi H, Shibasaki Y, Kamasawa N, Osumi M, Amachi T, Tanaka A. Construction of a starch-utilizing yeast by cell surface engineering. Appl Environ Microbiol. 1997;63(4):1362-6.

Nishitani T, Shimada M, Kuroda K, Ueda M. Molecular design of yeast cell surface for adsorption and recovery of molybdenum, one of rare metals. Appl Microbiol Biotechnol. 2010;86(2):641-8.

Potter CW. A history of influenza. J Appl Microbiol. 2001;91(4):572-9.

Sauter NK, Bednarski MD, Wurzburg BA, Hanson JE, Whitesides GM, Skehel JJ, Wiley DC. Hemagglutinins from two influenza virus variants bind to sialic acid derivatives with millimolar dissociation constants: a 500-MHz proton nuclear magnetic resonance study. Biochemistry. 1989;28(21):8388-96.

Shibasaki S, Ueda M, lizuka T, Hirayama M, Ikeda Y, Kamasawa N, Osumi M, Tanaka A. Quantitative evaluation of the enhanced green fluorescent protein displayed on the cell surface of Saccharomyces cerevisiae by fluorometric and confocal laser scanning microscopic analyses. Appl Microbiol Biotechnol. 2001;55(4):471-5.

Shigemori T, Nagayama M, Yamada J, Miura N, Yongkiettrakul S, Kuroda K, Katsuragi T, Ueda M. Construction of a convenient system for easily screening inhibitors of mutated influenza virus neuraminidases. FEBS Open Bio. 2013;3:484-9.

Skehel JJ, Wiley DC. Receptor binding and membrane fusion in virus entry: the influenza hemagglutinin. Annu Rev Biochem. 2000;69:531-69.

Stevens J, Blixt O, Glaser L, Taubenberger JK, Palese P, Paulson JC, Wilson IA. Glycan microarray analysis of the hemagglutinins from modern and pandemic influenza viruses reveals different receptor specificities. J Mol Biol. 2006a;355(5):1143-55.

Stevens J, Blixt O, Paulson JC, Wilson IA. Glycan microarray technologies: tools to survey host specificity of influenza viruses. Nat Rev Microbiol. 2006b;4(11):857-64.

Stevens J, Blixt O, Tumpey TM, Taubenberger JK, Paulson JC, Wilson IA. Structure and receptor specificity of the hemagglutinin from an $\mathrm{H} 5 \mathrm{~N} 1$ influenza virus. Science. 2006c;312(5772):404-10.

Stieneke-Grober A, Vey M, Angliker H, Shaw E, Thomas G, Roberts C, Klenk HD, Garten W. Influenza virus hemagglutinin with multibasic cleavage site is activated by furin, a subtilisin-like endoprotease. EMBO J. 1992; 11(7):2407-14.

Treanor JJ, Essink B, Hull S, Reed S, Izikson R, Patriarca P, Goldenthal KL, Kohberger R, Dunkle LM. Evaluation of safety and immunogenicity of recombinant influenza hemagglutinin (H5/Indonesia/05/2005) formulated with and without a stable oil-in-water emulsion containing glucopyranosyllipid A (SE + GLA) adjuvant. Vaccine. 2013;31(48):5760-5.

Tumpey TM, Maines TR, Van Hoeven N, Glaser L, Solorzano A, Pappas C, Cox NJ, Swayne DE, Palese P, Katz JM, Garcia-Sastre A. A two-amino acid change in the hemagglutinin of the 1918 influenza virus abolishes transmission. Science. 2007;315(5812):655-9. 
Ueda M, Tanaka A. Genetic immobilization of proteins on the yeast cell surface. Biotechnol Adv. 2000;18(2):121-40.

Van Reeth K. Avian and swine influenza viruses: our current understanding of the zoonotic risk. Vet Res. 2007;38(2):243-60.

Wang K, Holtz KM, Anderson K, Chubet R, Mahmoud W, Cox MM. Expression and purification of an influenza hemagglutinin-one step closer to a recombinant protein-based influenza vaccine. Vaccine. 2006;24(12):2176-85.
Webby RJ, Webster RG. Are we ready for pandemic influenza? Science. 2003;302(5650):1519-22.

WHO (2015) Cumulative number of confirmed human cases of avian influenza $\mathrm{A}(\mathrm{H} 5 \mathrm{~N} 1)$ reported to $\mathrm{WHO}, 2003-2015$

Zhou NN, Senne DA, Landgraf JS, Swenson SL, Erickson G, Rossow K, Liu L, Yoon K, Krauss S, Webster RG. Genetic reassortment of avian, swine, and human influenza A viruses in American pigs. J Virol. 1999;73(10):8851-6.

\section{Submit your manuscript to a SpringerOpen ${ }^{\circ}$ journal and benefit from:}

- Convenient online submission

- Rigorous peer review

- Immediate publication on acceptance

- Open access: articles freely available online

- High visibility within the field

- Retaining the copyright to your article

Submit your next manuscript at $\boldsymbol{s p r i n g e r o p e n . c o m ~}$ 